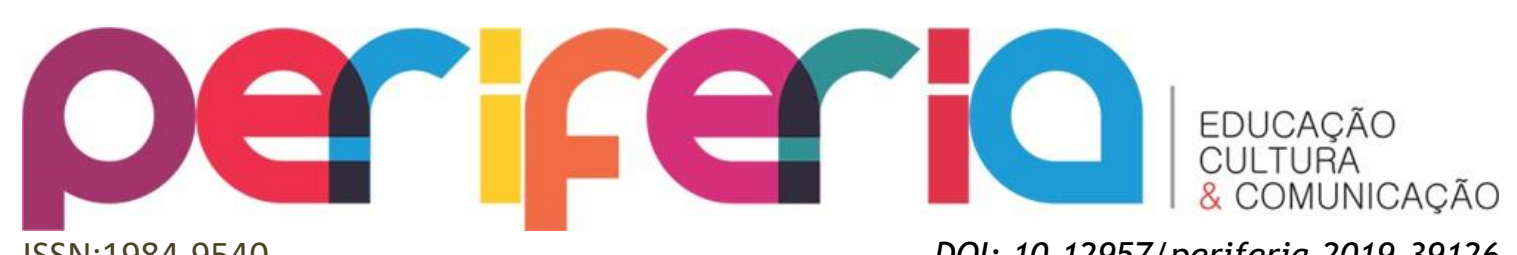

\title{
A ETNOGRAFIA DA ESCOLA: ENTRELAÇANDO VOZES, SUJEITOS, CONHECIMENTOS E CULTURAS
}

\author{
Luís Paulo Cruz Borges ${ }^{1}$ \\ Universidade do Estado do Rio de Janeiro \\ Paula Almeida de Castro ${ }^{2}$ \\ Universidade Estadual da Paraíba
}

\section{Resumo:}

A relação dos sujeitos da escola com o conhecimento e a cultura, analisados na perspectiva etnográfica, constitui o tema deste artigo. Tal relação está pautada pelo binômio cultura-conhecimento diante do processo de ensino-aprendizagem. Propõese, então, estudar e investigar com a perspectiva etnográfica, qual o papel da escola diante do conhecimento e da cultura, a partir das vozes dos seus próprios sujeitos. Refletir sobre a diversidade das práticas cotidianas de sala de aula pelo olhar da etnografia e das vozes de seus sujeitos possibilita configurar novas dimensões para a educação pública, contribuindo, sobremaneira, para o enfretamento do fracasso escolar. Pelos usos da observação participante, do diário de campo, de entrevistas etnográficas e de produção textual buscou-se compreender holisticamente como ocorre a relação entre sujeitos e conhecimento na escola pública mediada pela dimensão cultural. Por fim, propusemos uma discussão crítico-reflexiva sobre os saberes e fazeres percebidos a partir dos sentidos atribuídos pelos sujeitos da educação à ação pedagógica tomando a etnografia como abordagem teóricametodológica possível de fazer emergir as vozes silenciadas presentes no contexto escolar.

Palavras-chave: etnografia; escola; ensino-aprendizagem; conhecimento; cultura.

\footnotetext{
${ }^{1}$ Doutor em Educação pela Universidade do Estado do Rio de Janeiro. Mestre em Educação pela Faculdade de Formação de Professores da Universidade do Estado do Rio de Janeiro. Professor do Instituto de Aplicação Fernandes Rodrigues da Silveira da Universidade do Estado do Rio de Janeiro/ CAp-UERJ. E-mail: borgesluispaulo@yahoo.com.br

${ }^{2}$ Graduação em Psicologia pela Pontifícia Universidade Católica do Rio de Janeiro (2003). Mestrado em Educação pela Universidade do Estado do Rio de Janeiro (2006). Doutorado em Educação pela Universidade do Estado do Rio de Janeiro (2011). Professora Doutora de Formação de Professores da Educação Básica da Universidade Estadual da Paraíba Centro de Educação.
} 


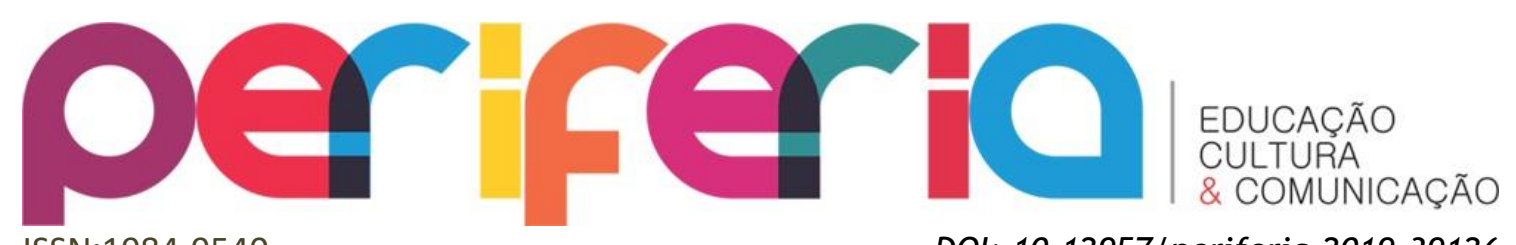

\title{
THE SCHOOL'S ETHNOGRAPHY: TEACHING VOICES, SUBJECTS, KNOWLEDGE AND CULTURES
}

\begin{abstract}
:
The relation of the subjects of the school with the knowledge and the culture, analyzed in the ethnographic perspective, is the theme of this article. This relationship is based on the culture-knowledge binomial of the teaching-learning process. It is proposed, then, to study and investigate with the ethnographic perspective, the role of the school in the face of knowledge and culture, based on the voices of its own subjects. Reflecting on the diversity of everyday classroom practices through the view of ethnography and the voices of the subjects makes it possible to configure new dimensions for public education by contributing, in particular, to the failure of schooling. Through the use of participant observation, the field diary, ethnographic interviews and textual production, we sought to holistically understand how the relationship between subjects and knowledge occurs in the public school mediated by the cultural dimension. Finally, we proposed a critical-reflexive discussion about how to know and to do made from the senses attributed by the subjects of education to the pedagogical action, taking the ethnography as a possible theoretical-methodological approach to emerge the silenced voices present in the school context.
\end{abstract}

Keywords: ethnography - school - teaching-learning - knowledge - culture. 


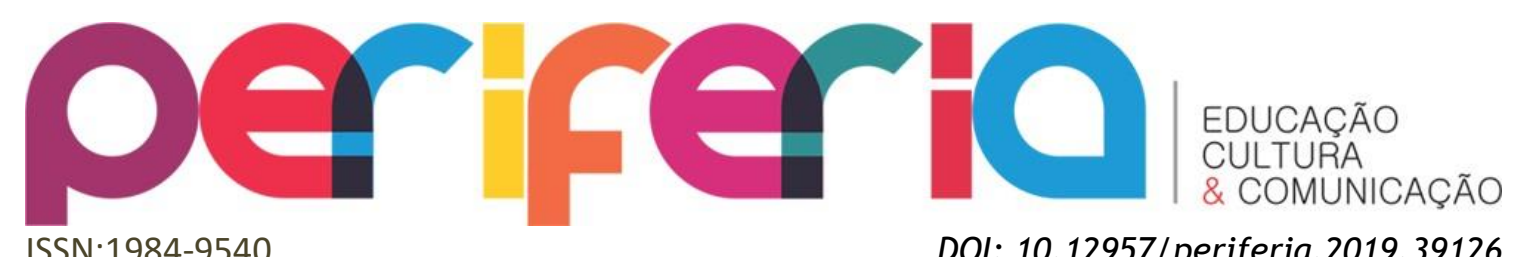

\section{LA ETNOGRAFÍA DE LA ESCUELA: ENTRELAZANDO VOZES, SUJETOS, CONOCIMIENTOS Y CULTURAS}

\section{Resumen:}

La relación de los sujetos de la escuela con el conocimiento y la cultura, analizados en la perspectiva etnográfica, constituye el tema de este artículo. Esta relación está pautada por el binomio cultura-conocimiento ante el proceso de enseñanzaaprendizaje. Se propone, entonces, estudiar e investigar con la perspectiva etnográfica, cuál es el papel de la escuela ante el conocimiento y la cultura, a partir de las voces de sus propios sujetos. La reflexión sobre la diversidad de las prácticas cotidianas de aula por la mirada de la etnografía y de las voces de los sujetos posibilita configurar nuevas dimensiones para la educación pública por contribuir, sobre todo, al enfrentamiento del fracaso escolar. Por los usos de la observación participante, del diario de campo, de entrevistas etnográficas y de producción textual se buscó comprender holísticamente cómo ocurre la relación entre sujetos y conocimiento en la escuela pública mediada por la dimensión cultural. Por último, propusimos una discusión crítico-reflexiva sobre los saberes y hacer percibidos a partir de los sentidos atribuidos por los sujetos de la educación a la acción pedagógica tomando la etnografía como abordaje teórico-metodológico posible de hacer emerger las voces silenciadas presentes en el contexto escolar.

Palabras clave: etnografía - escuela - enseñanza-aprendizaje - conocimiento cultura. 


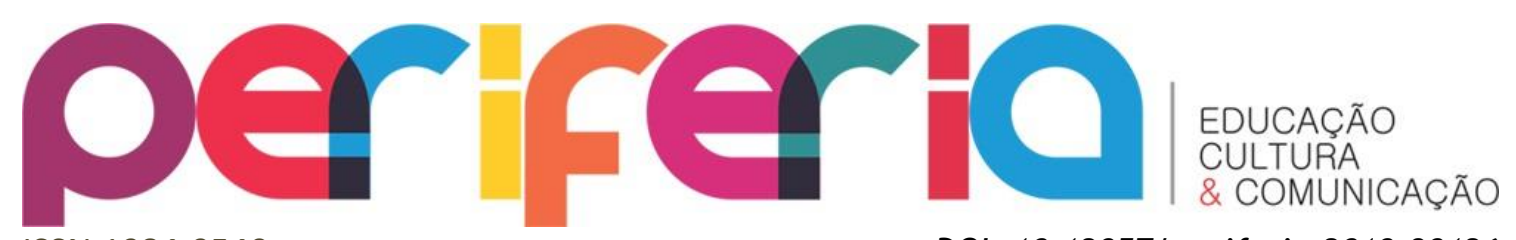

ISSN:1984-9540

DOI: 10.12957/periferia.2019.39126

\section{Introdução}

De que modo a etnografia contribui para conhecer a escola através de seus referenciais culturais, seus sujeitos, práticas e saberes? A etnografia, como processo de pesquisa, nos auxilia a conhecer as interações que acontecem no interior da escola e da sala de aula. A busca pela compreensão da relação dos sujeitos com o conhecimento e a cultura escolar, neste artigo, se dá pela utilização do referencial etnográfico de pesquisa na Educação, mais detidamente no campo da escola. É de entendimento que a etnografia da escola permite ao pesquisador desenvolver um olhar mais sensível para as questões que constituem este universo.

É diante da centralidade da cultura (HALL, 1997) que se pretende situar o juízo sobre a escola, também, como uma instituição cultural, em muito relacionada ao seu papel de convergência de discursos da vida social. Hall (1997), em uma perspectiva pós-colonial, nos fala de dimensões culturais interligadas, a saber, a globalização, as transformações da vida local e cotidiana, a relação entre identidades e subjetividades.

Neste entrelaçar das dimensões da cultura, entende-se conhecimento como espaço-tempo de contradição no âmbito da escola. Nas palavras de Lopes (1999, p. 25):

“[...] trata-se de um conhecimento selecionado a partir de uma
cultura social mais ampla, que passa por um processo de transposição
didática, ao mesmo tempo que é disciplinarizado; e, também,
podemos entender que constitui-se no embate com os demais saberes
sociais, diferenciando-se dos mesmos. Em síntese, o conhecimento
escolar define-se em relação aos demais saberes sociais, seja o
conhecimento científico, o conhecimento cotidiano ou os saberes
populares" (idem).

Partindo da relação conhecimento e cultura, destaca-se o viés etnográfico, com base na Antropologia, se utilizando de elementos para que os espaços educacionais sejam investigados de modo a possibilitar, como nos indica Dauster (2007, p. 31), a "construção de um saber híbrido ou de fronteira, além de um olhar mais complexo sobre os fenômenos educacionais". Ainda, como afirmam Mattos e Castro (2005), que a etnografia como abordagem teórico-metodológica utilizada para 


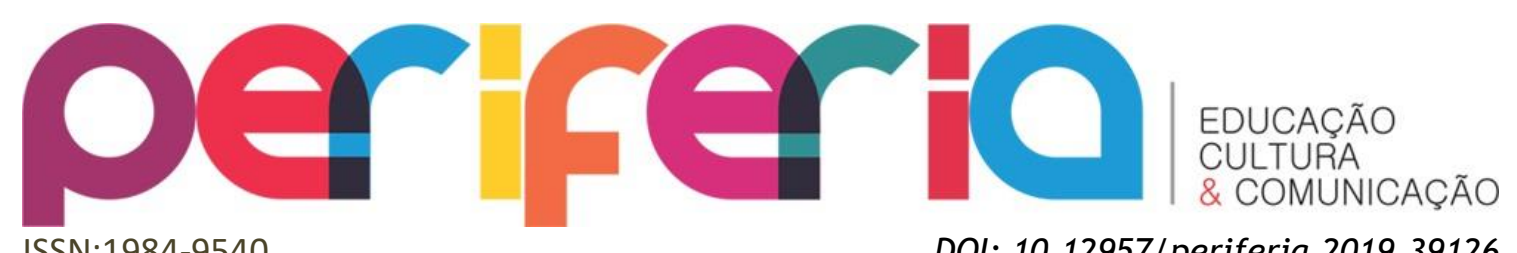

ISSN:1984-9540

DOI: 10.12957/periferia.2019.39126

estudar os processos de construção da realidade em sala de aula pode facilitar ao pesquisador um entendimento desse espaço.

0 pesquisador aproxima-se dos contextos escolares na tentativa de compreender os cenários e processos engendrados em seu interior. André (1996) explica que o uso da etnografia permite ao pesquisador "entender como se processam os mecanismos de dominação e de resistência, de opressão e de contestação ao mesmo tempo em que são veiculados e reelaborados conhecimentos, atitudes, valores, crenças, modos de ver e de sentir a realidade e o mundo" (p. 41).

Parafraseando Geertz (1989, p.32) pesquisar "a escola na escola" constitui-se como uma forma de retratar a realidade pesquisada de modo mais fiel possível. 0 autor explica que o antropólogo não estuda "as aldeias" ele estuda "nas aldeias" sendo, portanto, este o seu locus de estudo e não o seu objeto do estudo. Este processo possibilita aos leitores que "lá" não estiveram realizar suas próprias leituras da escola, sobre as experiências, valores e o "como" se constrói a realidade de alunos e professores.

Nos apoiamos no questionamento de Mattos (2006) sobre "quem pode fazer etnografia?" para buscar as conexões entre este tipo de pesquisa, o contexto escolar e as interações entre os sujeitos.

Buscando responder a pergunta - Quem pode fazer etnografia? -, diria que qualquer pesquisador culturalmente sensível pode fazê-la, embora minha resposta aos meus alunos seja: aquele que sente um grande desconforto na boca do estômago, com algo que não vai bem na sociedade e que não passa por ele ou ela muito facilmente, isto é, se algum fenômeno social está "caindo mal" para você, este é o seu objeto de estudo. Portanto, qualquer pesquisador bem treinado em etnografia e com uma pergunta socialmente relevante deve fazer pesquisa etnográfica (MATTOS, 2006, p.6).

Estudar as práticas de sala de aula de modo específico e de cada sujeito é, portanto, uma forma compreender os próprios processos das relações dos sujeitos com o conhecimento e a cultura escolar. 0 caminho que foi escolhido para mapear tais itinerários, foram os instrumentos de pesquisa: observação participante, entrevista, caderno de campo, produção textual e documentos oficiais. A partir da 


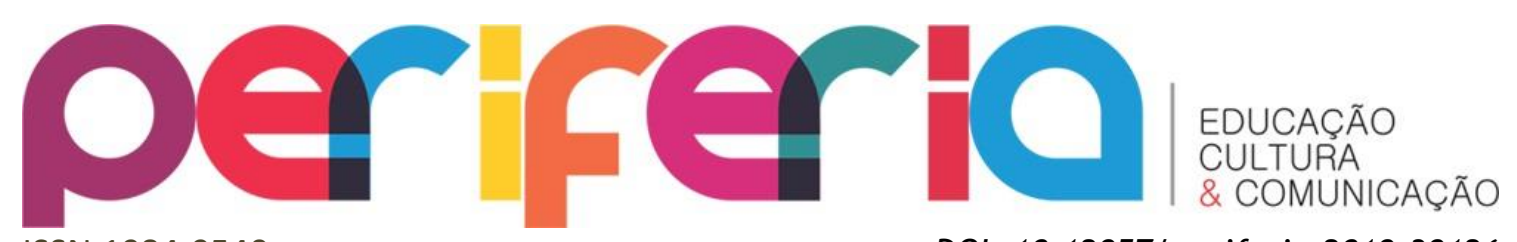

ISSN:1984-9540

DOI: 10.12957/periferia.2019.39126

abordagem etnográfica entende-se que os próprios sujeitos escolares são parte dessa construção de relação com o conhecimento e a cultura escolar.

A pesquisa de campo ocorreu com observações em sala de aula que foram desenvolvidas semanalmente durante sete meses em uma escola pública de Ensino Médio na rede estadual de Educação do Rio de Janeiro em Nova Iguaçu. Participaram da investigação estudantes do $2^{\circ}$ e do $3^{\circ}$ anos do Ensino Médio. As aulas observadas foram de Química em um regime de colaboração, ou seja, dentre o universo de docentes na escola, o professor de Química se dispôs a participar da pesquisa como colaborador. Dessa forma, as aulas, o pátio e a sala de professores foram espaços de observação de forma semanal.

Os jovens-estudantes são os sujeitos da pesquisa que, também, fazem parte da juventude do país. Jovens, meninos e meninas, afrodescendentes em sua grande maioria; oriundos das classes populares, sendo moradores da Baixada Fluminense, região com sérias questões sociais e econômicas, como por exemplo, falta de estrutura cultural como teatros e falta de saneamento básico, como água e esgoto. Região também marcada por traços da violência e presença de drogas ilícitas.

As observações geraram notas de campo, que geraram os relatórios de campo, e, enfim, sistematizaram-se os dados da pesquisa. Além da observação participante também foram entrevistados alguns estudantes, aos quais solicitamos que realizassem uma produção de texto perguntando sobre suas aprendizagens e também sobre suas expectativas a partir do inventário de saber de Charlot (2005), de forma que tivemos, como dados, a observação participante com a descrição densa, entrevistas etnográficas e a produção textual, além de documentos produzidos pela Secretaria Estadual de Educação.

Após o campo, tivemos uma etapa de sistematização e análise de dados, foi preciso retornar às entrevistas realizadas e às descrições do caderno de campo para compor as análises do trabalho e levantar as categorias temáticas. Nesse processo também se elegeram outras informações para compor o panorama dos dados: informes sobre a instituição em redes sociais, análise de reportagens em mídias, notas em associações, falas de estudantes em vídeos. Indica-se que a escola produz e também é produtora de uma conjuntura compreendendo aqui uma abordagem 


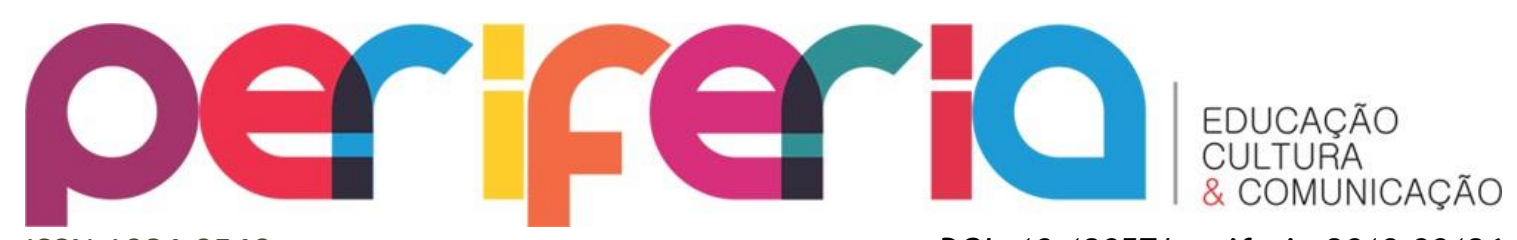

dialógica da pesquisa com idas e vindas. Após a organização em blocos de textos, os mesmos foram lidos, relidos e sistematizados em categorias em consonância com o Atlas.ti. Contudo, o olhar do pesquisador no processo artesanal de feitura da pesquisa ainda foi a principal forma de análise dos dados (MILLS, 2009).

A última etapa do processo de produção do relato etnográfico é escrever o texto final de um processo de formação para a pesquisa reflete um desafio proposto em "estar lá" e escrever aqui, entendendo o antropólogo como autor (GEERTZ, 2002). A escrita final pressupõe idiossincrasias que aparecem ao longo do texto. Pressupõe analisar e compreender a partir da ideia de reimaginação posta no plano cultural da significação de sentidos. Escrever o texto etnográfico é criar a emergência de sentidos possíveis, mas também impossíveis para quem não viveu o campo tal qual o etnógrafo. Importante destacar que há rasuras, lacunas, contradições, sendo a etnografia um saber de fronteira, ela nos coloca em perigo, pois não permite uma fixação. Mas, de forma emblemática, da fronteira se pode ver um horizonte mais largo, mais possível.

\section{O papel do etnógrafo na compreensão da narrativa etnográfica}

A opção por utilizar a abordagem etnográfica, neste estudo, reflete a busca pela perspectiva do sujeito pesquisado e a compreensão da relação entre a etnografia, o pesquisador e o campo. Considerou-se, além dos sujeitos pesquisados neste estudo, a condição de aluno vivenciada por [nós] pesquisadores nos diferentes níveis do percurso acadêmico.

Considera-se na Etnografia o deslocamento como ação que é promovida quando inicia-se o trabalho de campo, o contato com os sujeitos e a tentativa de nos emaranharmos em uma cultura diferente da nossa. A esse respeito, se diz do processo de estranhamento que é, de certo modo, necessário para encontrar, com efeito, o entendimento esperado sobre as diversas formas de conceber, como nesse estudo, a relação do sujeito com o conhecimento e a cultura.

Neste estudo, é possível destacar dois aspectos que situam o sujeito aluno e a escola sob o aspecto único, singular de suas trajetórias. 0 primeiro aspecto estaria 


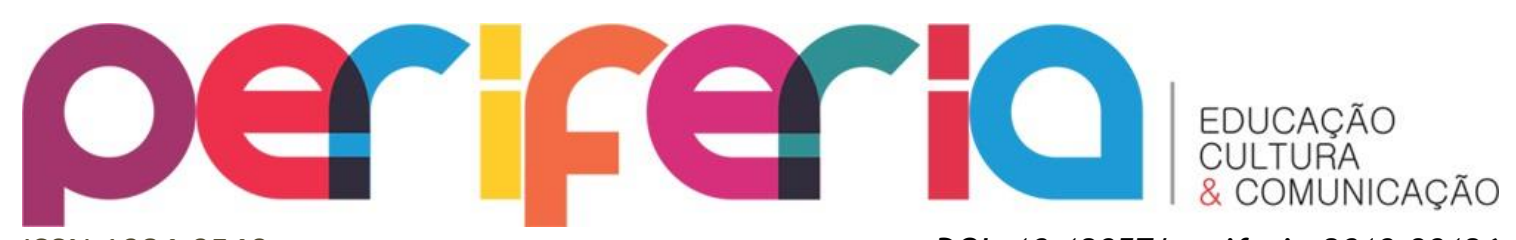

justamente em considerar que alunos e alunas no processo de serem e se tornarem, constroem em suas narrativas a singularidade das experiências vivenciadas em ambientes educacionais. O segundo estaria relacionado com a própria vivência do pesquisador, enquanto sujeito aluno, indicando uma possibilidade de compreender, em ambientes educacionais diversos, o processo de outros sujeitos se tornarem alunos. Isso se dá pela atitude do pesquisador com a qual “outros sistemas de referência que não são os seus próprios seriam por ele percebidos” (DAUSTER, 2007, p.15), possibilitando ao pesquisador ampliar a sua percepção dos modos de pensar, sentir e se fazer distintas daquelas que são suas.

O pesquisador busca espaços e sujeitos para aproximar-se de suas realidades com a finalidade de compreendê-los. Geertz (2008) ainda propõe um questionamento, que podemos tomar como no próprio processo de pesquisar, quanto a possibilidade de “indivíduos pertencentes a uma determinada cultura" (pesquisadores) serem capazes de, possivelmente, compreender "indivíduos que pertencem a outra" (sujeitos investigados) (p.223). Atividade esta, que permanece sem uma resposta, mas que Geertz a compara aos espectadores de um espetáculo de sombras; "o que os olhos veem e o que ouvem os ouvidos não é o mesmo que a mente percebe" (p.223). Refletir sobre o material empírico requer do pesquisador um "aprofundar" constante na teoria que servirá de aporte teórico-epistemológico.

“Fazer etnografia”, explica Geertz (1989), vai além de uma viagem em busca de lugares e sujeitos desconhecidos, passando por uma descrição densa do campo estudado e chegando a uma tentativa de "ler (no sentido de construir de uma leitura de) um manuscrito estranho, desbotado, cheio de elipses (...) escrito não com os sinais convencionais do som, mas com exemplos transitórios de comportamento modelado" (p.20). A ideia de Geertz (1989) versa sobre os processos de tradução que todo etnógrafo precisa realizar, desvendar mundos por meio da descrição densa.

Autores (ANDRÉ, 1996; MATTOS, 1992; 2001) que utilizam o referencial etnográfico nas suas pesquisas, definem etnografia como a descrição de uma cultura, a preocupação com o significado, com a maneira própria com que as pessoas veem a si mesmas, as suas experiências e o mundo que as cerca; “o pesquisador deve tentar apreender e retratar essa visão pessoal dos participantes” (GEERTZ, 1989, p.29). 


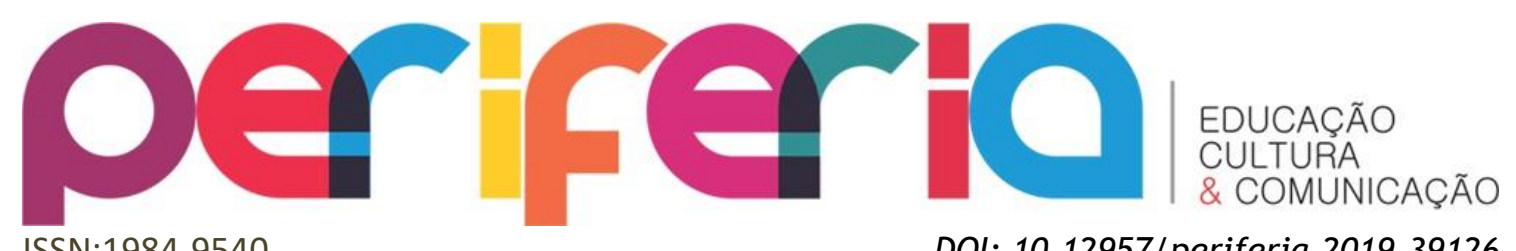

Mattos e Castro (2010) afirmam que é a etnografia holística que oferece referencial necessário para situar a perspectiva dos participantes na pesquisa ao pressupor aspectos da cultura como dimensão emblemática para a compreensão da vida em sociedade. Estes aspectos incluem: organização social, econômica, estrutura familiar, religião, políticas práticas, rituais, padrões de aculturamento e de comportamento ritualizados (PELTO, 1970, p. 18). Pressupõe ainda, que os diferentes aspectos de uma cultura formam um conjunto único e unificado, de peças interdependentes (MEAD, 1973, p. 246). O foco desses estudos está na cultura dos grupos bem como em descrever, analisar e compreender esta cultura como um todo e ao mesmo tempo como singular.

A opção pelo referencial etnográfico ultrapassa a intenção de captar pelo olhar do pesquisador o ponto de vista do aluno, implica em uma aproximação visando conhecer as práticas que configuram o quadro de referências do processo de construção desse aluno enquanto alunos e dos modos de pertencimento exigidos pela escola. Como afirma Geertz (1989) o etnógrafo busca em seus informantes o que não é capaz de perceber, utilizando em seus relatos as expressões "com que", ou "por meios de que”, ou "através de que” para descrever o que é percebido pelo "outro".

É, pois, na condição de "espectador", que o pesquisador utilizando o referencial etnográfico procura descrever o espaço da escola. Na medida em que o uso da etnografia nos estudos em Educação, cria novos parâmetros para se (re)pensar as práticas escolares. Sugere-se que o interesse da pesquisa não deve estar somente voltado para o ato de pesquisar, mas para a produção de conhecimento. Ao produzir conhecimento percebe-se a fronteira de onde se está e para onde é possível caminhar.

Neste escopo, a pretensa invisibilidade, assim como a neutralidade do pesquisador em relação ao seu campo de pesquisa, é que permite encontrar justamente na ideia de estranho, sendo assim, a chave para entender os problemas e soluções que surgem no ambiente escolar envolvendo seus atores na responsabilidade de responder às expectativas por resultados “esperados” de sucesso que acabam, muitas vezes, em fracasso. 


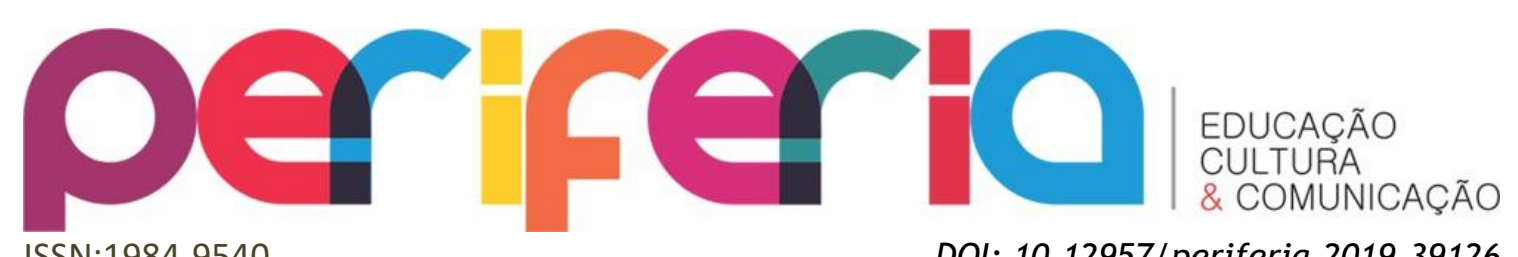

ISSN:1984-9540

DOI: 10.12957/periferia.2019.39126

Qual a importância de conhecer o aluno da Educação brasileira através da abordagem etnográfica? Quais são as práticas e propostas pedagógicas pelas quais o conhecimento escolar é elaborado pelo aluno? Como se dá a elaboração desse conhecimento? Estas são algumas das questões que direcionam o olhar do pesquisador no contexto de pesquisa.

A proposta de ouvir o aluno encontrou nos estudos etnográficos uma via pela qual suas individualidades são evidenciadas na totalidade da escola, para desse modo criar possibilidades de se repensar as práticas de sala de aula. Esta proposta surge como uma resposta aos questionamentos sobre a validade de emergir as vozes dos sujeitos e ouvi-los. Neste sentido, nessa pesquisa a voz do sujeito significa ouvir o que eles têm a dizer sobre as questões propostas para a realização do estudo, ou seja, como o sujeito da pesquisa elabora e reelabora o seu saber sobre o objeto de pesquisa, (re)significando-o. A palavra carrega um dizer único. É necessário ouvir. Para compreender o sujeito é antes preciso ouvir e analisar a sua fala a partir dela mesma. As análises partem do que ele expressa através de sua narrativa. A interpretação se dá pelo envolvimento do pesquisador com o sujeito da pesquisa de modo a perceber as nuances do processo de fazer sentido de sua fala.

Dessa forma, mapeando e clarificando quem são os sujeitos incluídos no sistema de ensino através de suas subjetivações identitárias, poderá ser explicado o "como" dos processos de ensino-aprendizagem. Ainda que, pela composição das palavras "ensino-aprendizagem", estas pareçam trafegar numa via com única direção e velocidade, mas implicam em sujeitos e modos de funcionamento diferenciados que necessariamente conduzirão a resultados inesperados. Compreender o aluno poderá contribuir para a melhoria dos resultados do ensino e aprendizagem e levar a processos de inclusão mais realísticos do ponto de vista cognitivo, nos quais o indivíduo possa ser reconhecido como sujeito do seu próprio conhecimento.

Entende-se que é pela dinâmica das interações entre os processos educacionais e seus sujeitos que é produzido o conhecimento no qual a pesquisa concorre para contribuir com explicações e compreensão sobre os fenômenos sociais observados neste espaço-tempo de relações. 


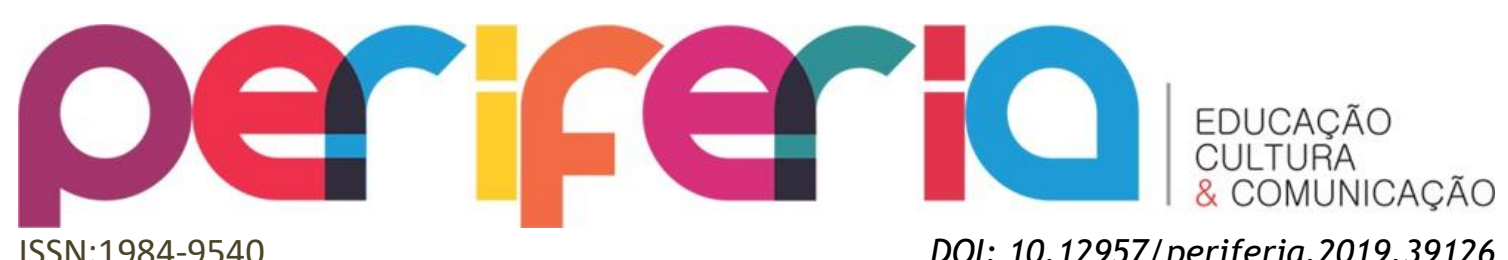

\section{As vozes da escola: o cenário etnográfico}

As vozes da escola, ora apresentadas, destacam três perspectivas acerca das explicações dos alunos sobre a interação entre cultura e conhecimento pautadas nos eixos das relações de amizade, processos de ensino-aprendizagem e aspirações de futuro.

Ao passo que a pesquisa se desenvolve, também se desenvolvem diversas compreensões sobre o objeto de estudo proposto. Aqui, a relação dos jovensestudantes do Ensino Médio de uma escola pública estadual com o conhecimento escolar. A etnografia torna-se, também, um paradigma que, igualmente, se desenvolve com o objeto de estudo.

Mattos (2017) chama atenção para a ideia de que a etnografia, em tempos de caos, tem ganhado destaque no meio acadêmico por tornar-se uma condição necessária que vem dando sentido à pesquisa educacional na e sobre a escola. A autora continua nos instigando a pensar que "a beleza e o mistério da busca do etnógrafo é encontrar histórias inesperadas, as histórias que desafiam as teorias prontas" (MATTOS, 2017, p. 121). 


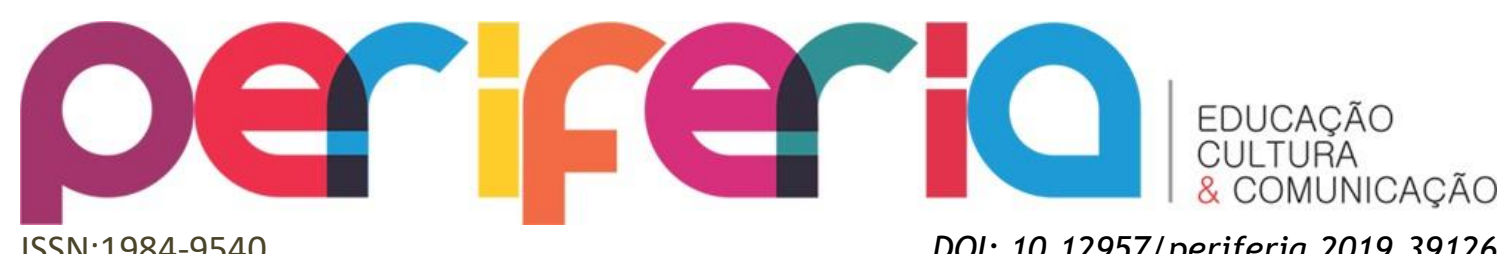

Figura 1 - Relação entre etnografia e produção de conhecimento

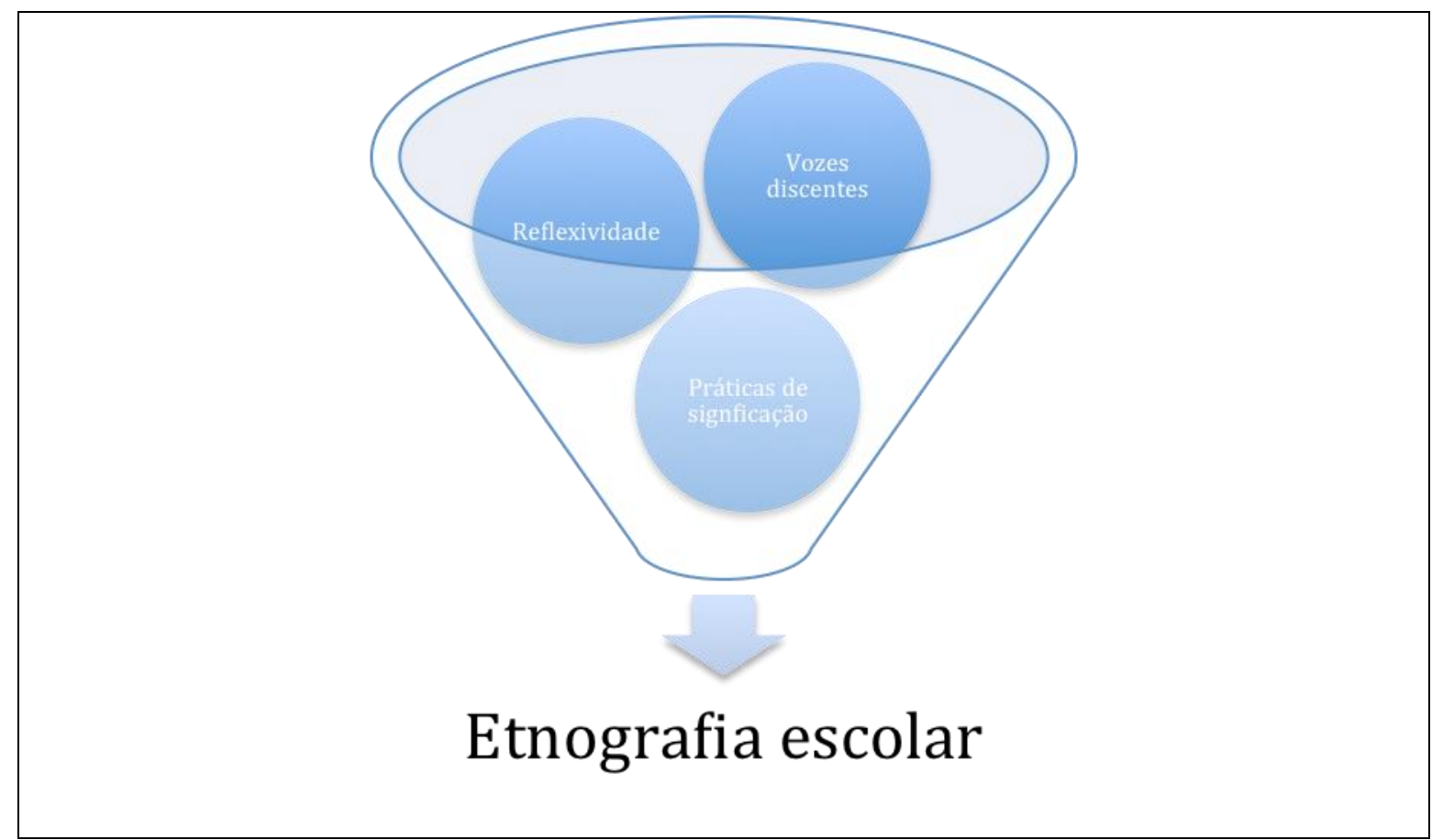

Fonte: BORGES, 2018.

A reflexividade proposta pela etnografia aqui exercida, auxilia no entendimento de que o processo de produção de conhecimento na pesquisa educacional é um compósito da relação reflexividade - vozes discentes - práticas de significação na escola. Tais dimensões mobilizam o questionamento sobre que escola e que conhecimento - escolar - hão de existir no futuro.

Bhabha (2011), mais uma vez, sinaliza para a ideia de que, ao olhar para trás, vamos indo para frente. Esse paradoxo proposto é uma forma de, a partir da linguagem, construir uma via possível como chave de resposta. 0 existir, talvez, é o que está permeado, ou mesmo impregnado, de sentidos que precisam transcender a ideia de verdade colonial moderna. Aqui, argumenta-se, então, que a escola é o lugar da existência e resistência de diversas formas de crenças e conhecimentos presentes hoje no mundo moderno: docentes resistindo em suas redes e estudantes em resiliência.

À época da pesquisa, ano corrente de 2015 , já se ventilavam possibilidades de mudança/reforma para o Ensino Médio. Algo que, efetivamente, se concretizaria no ano de 2017. No entanto, em uma conversa em sala de aula, alguns estudantes falam 


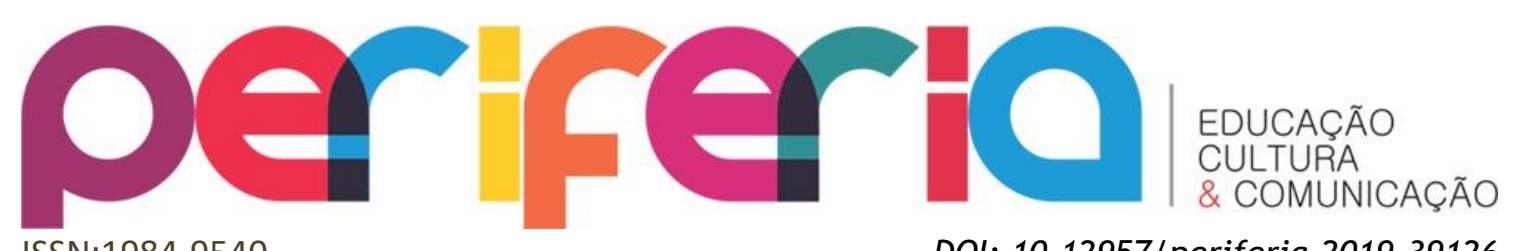

ISSN:1984-9540

DOI: $10.12957 /$ periferia.2019.39126

sobre o Exame Nacional de Avaliação do Ensino Médio (ENEM) e também sobre uma mudança na estrutura do sistema de ensino. As falas abaixo, de duas jovensestudantes, refletem essas compreensões de que "o novo" e o futuro se entrelaçam, permeando novas compreensões de que escola e que conhecimento, ou conhecimentos, existirão.

Sou a favor de um novo ensino médio, porém precisamos ser preparados para o futuro, porém não sabemos o que nos espera (Fala de Nina Simone em sala de aula, registro de campo, 2015).

Um novo ensino médio nos dará mais oportunidades para nossos futuros como: bolsas para escolas militares, bolsas para a faculdade, mais ensinos para passar no ENEM, mais cursos gratuitos, mais conhecimentos gerais, mais oportunidades para arranjar um trabalho e entre outras oportunidades... (Fala de Teresa, registro de campo, 2015).

A primeira fala, de Nina, evidencia que "precisamos estar preparados para o futuro". Contudo, a mesma jovem estudante indica que "não sabemos o que nos espera". A imprevisibilidade e instabilidade do porvir coloca em relevo uma dimensão importante das ações cotidianas na vida escolar, a alegoria do tempo. A existência que se dá pelo imprevisível ou mesmo pelo instável. Como planejar e se saber em uma perspectiva instável e desafiadora? Assim, Pinar (2016) indica que a temporalidade pode ser encarada como uma alegoria possível de análise das relações.

\begin{abstract}
Alegoria reconhece o conhecimento acadêmico como sendo importante para seu próprio benefício, até mesmo porque implica sua importância educacional. A alegoria ressalta que nossas vidas individuais são estruturadas por círculos de influência cada vez mais alargados: da família, passando pelos amigos e chegando aos nossos conterrâneos (PINAR, 2016, p. 209).
\end{abstract}

A escola poderia ser uma alegoria dessa dimensão temporal em que se vive 0 ontem, o hoje e o amanhã? Dessa forma, as contradições trazidas por Nina são necessárias para se pensar "assim como o futuro, o pensamento sério e criativo é 


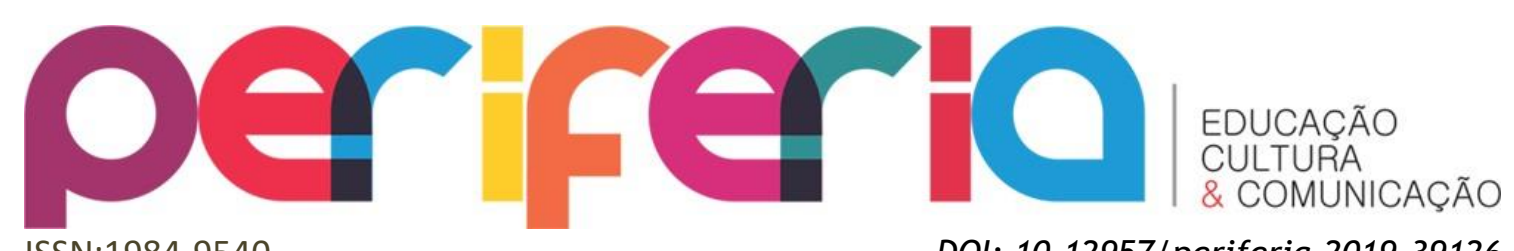

quase sempre enigmático, às vezes contraditório, até mesmo incalculável” (PINAR, 2016, p. 213).

A segunda fala, de Teresa, evidencia uma relação entre o que é e a possibilidade de novas conquistas. Bolsa para outras escolas e para a faculdade, mais ensino, aqui entendido possivelmente como conhecimento, para "passar no ENEM". Tal fala traz como destaque a dimensão da avaliação na tríade escola-conhecimentoavaliação. A avaliação ganha uma multiplicidade de sentidos que são trazidos na fala de Teresa na compreensão de avaliar para aprender, passar, conquistar, arranjar trabalho, ter oportunidade. Vasconcellos (2016) já evidenciara que a multiplicidade de sentidos da avaliação no contexto escolar é um importante objeto de estudo, pois a partir dela podem-se compreender processos mais complexos que envolvam, desde o cotidiano escolar até as políticas públicas de educação. A narrativa destaca a existência pela possibilidade da materialização do conhecimento.

Ainda na ideia de existência da escola e do conhecimento, retoma-se uma compreensão de Bhabha (2011) sobre o entrelugar das culturas a partir das memórias e narrativas de si. Dessa modo, a fala de Lucas Rebouças, em sua produção textual, revela uma ideia de aprender significada de diferentes modos e espaços-tempos: igreja, vida, a escola... revela-se uma dimensão transcendente do existir.

\begin{abstract}
Muita coisa já me aconteceu, por mais que pareça a minha história é bastante grande, aprender na igreja é um bem muito maior, mas tem coisa que a gente aprende na vida, a escola te ensina e ajuda a ter um futuro melhor, mas o mundo também vai te ensinar, caminhos se escolhem, passo a passo a gente cresce, se reproduz, envelhece e morre. Aprender faz parte da nossa vida, temos muito que aprender com Deus e com o mundo e todos os dias aprendemos mais, o mundo esta ai para derrubar, mas minha fé em Cristo sempre vai prevalecer, esse é um motivo para eu estar feliz, uma razão eterna para viver (Relato de Lucas, produção de texto, $3^{a}$ série do Ensino Médio).
\end{abstract}

Ao entrelaçar vida, fé e futuro, Lucas Rebouças destaca uma dimensão importante das relações e condições materiais presentes na existência da escola e do conhecimento: a dimensão da transcendência. Embora se advogue a ideia que as instituições públicas precisam, e devem, ser laicas, os seus sujeitos em trânsito atravessam essa premissa colocando subjetividade e significação a partir de si. 


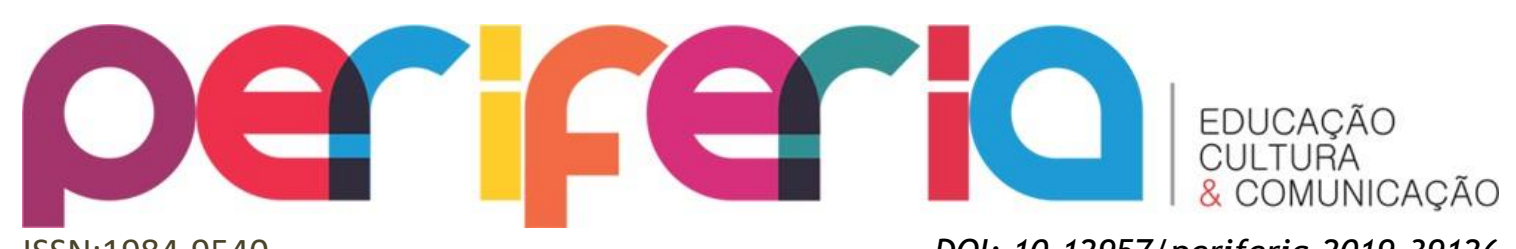

ISSN:1984-9540

DOI: $10.12957 /$ periferia.2019.39126

Ao falar que "temos muito que aprender com Deus e com o mundo", Lucas significa o conhecimento a partir da experiência do espiritual. No entanto, é sobre a razão da ciência que esperamos as compreensões de mundo (PEREIRA, 2012). Como então aliar ciência moderna à transcendência existente e presente no dia a dia da escola?

É a partir de Bhabha (2011) que pressupomos uma compreensão de sujeito que, na fronteira entre a razão e a emoção, ou mesmo, entre o conhecimento proposto pela ciência e pela fé, se posiciona. É o entrelugar cultural que Lucas Rebouças toca em sua história de si, mas que permeia uma "compreensão teórica da cultura como diferença” (BHABHA, 2011, p. 83), utilizando-se da própria ideia de tempo e conhecimento. Dito de outra forma, a voz do jovem estudante do Ensino Médio faz ressoar uma dimensão que a pesquisa não tinha se proposto a pensar, mas que, ao fazer parte do campo, faz saltar uma questão de análises progressivas das categorias que são defendidas, consubstanciadas e retroalimentadas pelo indizível, que aqui foi dito.

O relato de Lucas é pungente porque diz do lugar de uma outra visão e compreensão do mundo, que também é presente na escola, disputando novos sentidos sobre as narrativas que envolvem o conhecimento escolar. Nas palavras de Bhabha (2011, p. 91), tais falas "desdobram a cultura parcial a partir da qual emergem para construir visões de comunidades e versões de memórias e histórias". É a vida que, pulsando fora da escola, também interfere na instituição.

Por fim, temos uma dimensão política do existir. Uma dimensão pautada no movimento estudantil em todo país de que "ocupar, lutar e resistir", são também formas de existir na instituição escola. Nesse sentido, evidenciam-se dois fragmentos sobre a dimensão politica pautada na voz que ressoa no ambiente escolar e fora dela. A fala é de uma participante da pesquisa que, em uma entrevista, relatou seus planos para o futuro, mas também a relação entre política, justiça e transparência.

Meu plano para o futuro é viver em um mundo em que a política seja justa e limpa, cursar medicina, ter filhos e desejo que eles cresçam em um mundo sem preconceitos (Entrevista com Tereza Cristina, estudante da $1^{\text {a }}$ série do Ensino Médio). 


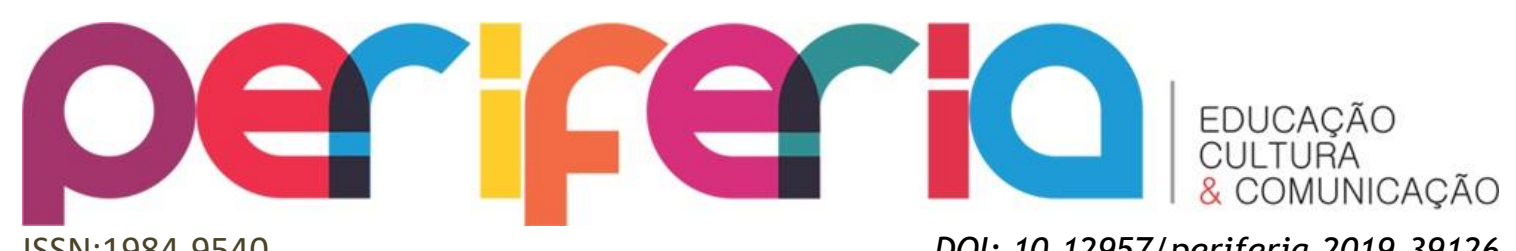

ISSN:1984-9540

DOI: 10.12957/periferia.2019.39126

A estudante fala sobre um plano pessoal para o futuro, micro, mas que se confunde com um plano macrossocial. Deseja na sua relação pessoal com o mundo cursar medicina e ter filhos, mas que eles possam crescer em um mundo melhor. Contudo, prenuncia sua fala evidenciando que esse mundo tenha uma "política justa e limpa". Qual seria o papel da educação, da escola e do conhecimento nesse contexto? Possivelmente, haveria um caminho a seguir para a resposta esperada. Porém, é lançada a reflexão e suas problematizações sem previsão de um coro uníssono.

As falas acima são vozes propositivas sobre formas de pensamento, construções de subjetividades, sobre utopias que desejamos. O projeto universal de escola, dessa forma, deixa à margem diferentes sentidos para a ideia de político. Algo que aqui se deseja pensar numa abordagem da noção de poder existir. É no caminho da existência de cada sujeito presente, diante das diferentes realidades sociais que permeiam o ambiente escolar que se pensa também a defesa do próprio conhecimento escolar. Na esteira das palavras de Mignolo (2008), a escola pode se pensar de forma desobediente, gerando, assim, uma desobediência epistêmica presente em seus currículos e sujeitos.

As vozes discentes, aqui presentes, são formas de teorizações capazes de tornar visíveis as experiências de seus sujeitos. Qual seria a função da escola? A proposição durkhemiana, ainda presente nos dias de hoje, revela que o lugar da alteridade precisa emergir, mas que contraditoriamente já é presente nos sujeitos escolares que se constituem, em necessidade primordial, para nos fazer pensar em uma educação do presente e do futuro.

\section{Considerações finais: refletindo sobre o futuro da escola}

Pesquisar a escola na escola constituiu-se pela possibilidade de ouvir e refletir sobre as vozes dos sujeitos que, nas interações, entrelaçam culturas e conhecimentos como produção escolar. Produção esta que é, muitas vezes, negligenciada na escola em função do cumprimento de currículos em dias letivos. 0 que os alunos trazem e 


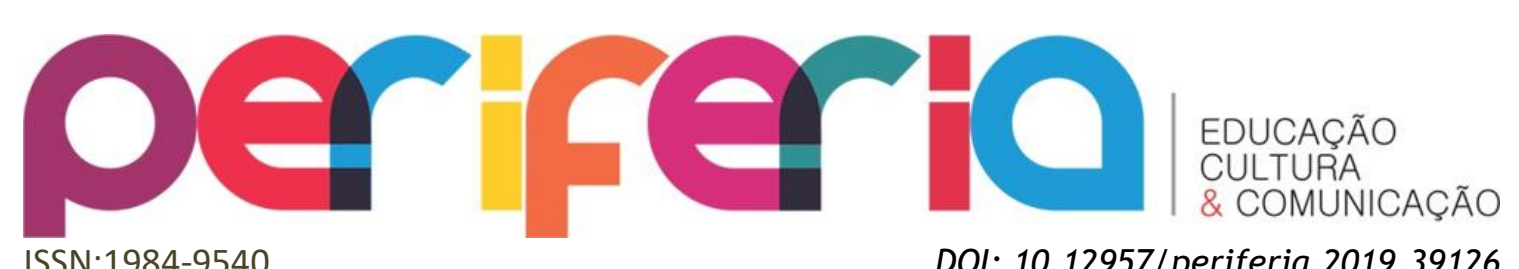

produzem na escola é mensurado em termos de avaliação, sendo reduzidos ao quanto valem e representam nos índices educacionais.

É crescente o aumento de pesquisas que são realizadas em escolas públicas no Brasil, nos mais diferentes programas de pós-graduação ou através de editais de pesquisa. Cabe destacar que são poucos os que privilegiam as vozes dos alunos como sujeitos primários na pesquisa. Observar o contexto escolar sem que os próprios sujeitos informem sobre o local confere ao pesquisador os dados necessários para sua pesquisa, mas não se apoiam na perspectiva do outro para interpretar aquele local, reconhecido por todos os sujeitos escolarizados, mas que guarda um semnúmero de explicações e vivências. A etnografia, enquanto abordagem teóricometodológica de pesquisa, permite o acesso ao campo da escola e, mais detidamente, aos sujeitos e suas explicações sobre as situações cotidianas observadas. É pela possibilidade de estranhar o familiar que o pesquisador etnográfico encontra as respostas para informar aos leitores sobre a realidade a partir das explicações dos sujeitos da pesquisa, os alunos.

Reflexividade, vozes discentes e práticas de significação formam o tripé em que se ancorou essa pesquisa para buscar o entendimento sobre a cultura e a produção do conhecimento entre os sujeitos da pesquisa. O entendimento deles, expressos nos trechos das entrevistas, indicam que o futuro a partir da educação está alicerçado nas políticas públicas que possam oferecer bolsas de estudo e acesso ao ensino superior o que viabilizaria uma vida em uma sociedade justa e livre de preconceitos. Entrelaçam, ainda, a fé e a crença num futuro de possibilidades.

Explicações que refletem a cultura como diferença que afasta os indivíduos, ao contrário de ser o entendimento de que somos diferentes com possibilidades de trocas significativas para o enriquecimento das experiências coletivas. Cada aluno carrega em si as experiências que acumulou ao longo dos anos de escolarização e memória das situações de interação, que possibilitaram trocas afetivas e sociais reproduzidas ao longo da vida. As aspirações de futuro se pautam mais no que socialmente terão como possibilidade, distante da pauta de aprovação escolar em que estão invariavelmente submetidos. 


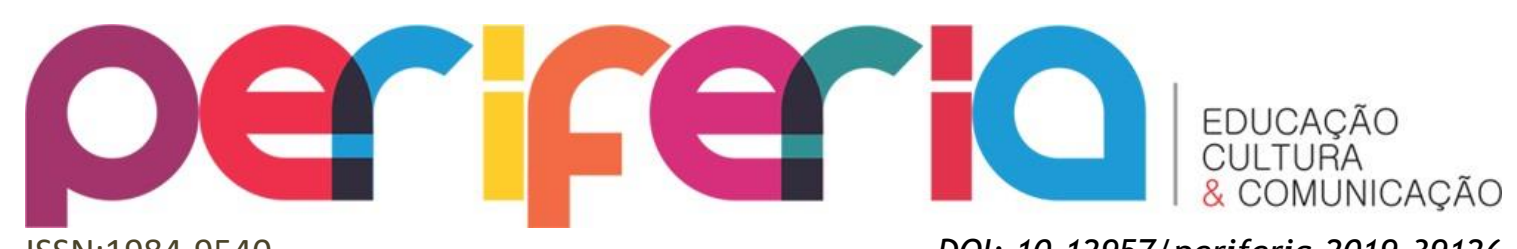

ISSN:1984-9540

DOI: 10.12957/periferia.2019.39126

Sinalizamos, neste artigo, o modo como a etnografia da escola oferece pistas para o entendimento, ao fazer emergir as vozes dos sujeitos, sobre o próprio processo de escolarização pautado no entrelaçamento entre cultura e produção do conhecimento. Esse entrelaçamento conduz para uma reflexão crítica sobre a realidade da escola reconhecida nas explicações dos sujeitos.

Entendemos que a etnografia ao aproximar o pesquisador da realidade da escola o conduzirá às múltiplas experiências escolares existentes. Estes achados de pesquisa podem servir de referencial às políticas públicas em educação, de modo que assegurem qualidade aos processos educacionais para uma vivência de sociedade mais justa, com igualdade de oportunidades respeitando a diferença que nos constitui como sujeitos em si.

\section{Referências}

ANDRÉ, M. E. D. A. Etnografia da prática escolar. Campinas: Papirus, 1996.

BHABHA, H. O Bazar Global e o Clube dos Cavaleiros Ingleses. Rio de Janeiro: Editora Rocco, 2011.

BORGES, L.P.C. O futuro da escola: uma etnografia sobre a relação dos jovens com o conhecimento escolar. 2018. $151 \mathrm{f}$. Tese (Doutorado em Educação) - Faculdade de Educação, Universidade do Estado do Rio de Janeiro, Rio de Janeiro, 2018.

CHARLOT, B. Relação com o saber, formação dos professores e globalização: questões para a educação hoje. Porto Alegre: Artmed, 2005.

DAUSTER, T. Um saber de fronteira - entre a antropologia e a educação. In: DAUSTER, T. (org.). Antropologia e educação: um saber de fronteira. Rio de Janeiro: Forma \& Ação, p.13-36, 2007.

GEERTZ, C. A interpretação das culturas. Rio de Janeiro: Guanabara, 1989.

GEERTZ, C. Estar lá: a antropologia e o cenário da escrita. In: GEERTZ, Clifford. Obras e vidas: o antropólogo como autor. Rio de Janeiro, Editora da UFRJ, p.11-40, 2002.

HALL, S. A centralidade da cultura: notas sobre as revoluções culturais do nosso tempo. Educação \& Realidade, Porto Alegre, v. 22, n², p. 15-46, jul./dez., 1997.

LOPES, A. C. Conhecimento escolar: ciência e cotidiano. 1ed. Rio de Janeiro: Editora da UERJ, 1999. 


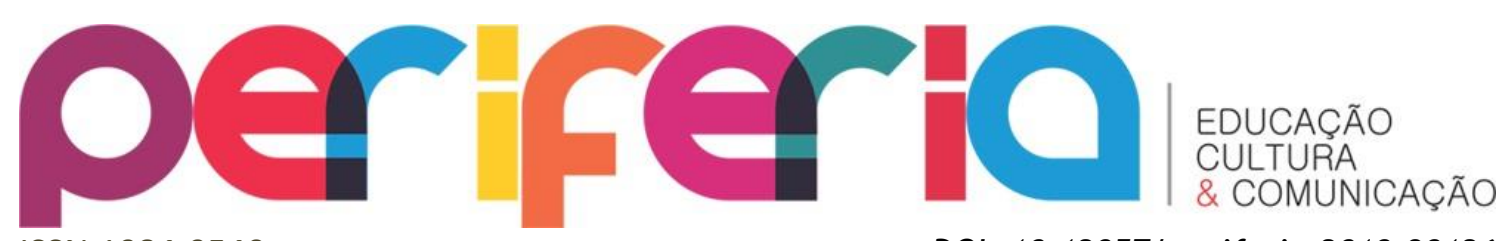

ISSN:1984-9540

MATTOS, C. L. G. Fazendo etnografia em tempos de caos: o movimento a "voz do aluno" como impulsionador de mudanças na escola. In. Universidade e participação: inclusão, ética e interculturalidade. Monica Pereira dos Santos, Ângela Maria Venturini, Jose Guilherme de Oliveira Freitas, Elisa Macas, Regina Maria de Souza Correia Pinto, (organizadores), Curitiba: CRV, p. 109-127, 2017.

MATTOS, C. L. G. de. Estudos etnográficos da educação: uma revisão de tendências no Brasil. In: CLARETO, S. M. Pesquisa Qualitativa: atualidades e perspectivas. Juiz de Fora, Educação em Foco, vol. 11, n.1, p. 169-187, mai/ago., 2006.

MATTOS, C. L. G de. A abordagem etnográfica na investigação cientifica. Espaço Informativo Técnico do INES/MEC, Rio de Janeiro, v.s. n.16, p. 1-20, 2001.

MATTOS, C. L. G. de. Picturing School Failure: a study of diversity in explanations of education difficulties among rural and urban youth in Brazil. Thesis (PhD in Education) University of Pennsylvania: UMI Bill\& Howell, 1992

MATTOS, C. L. G. de ; CASTRO, P. A. Entrevista como instrumento de pesquisa nos estudos sobre fracasso escolar. In: Anais IV Seminário Internacional de Pesquisa e Estudos Qualitativos - Pesquisa Qualitativa: rigor em questão, Rio Claro, 2010.

MATTOS, C. L. G. de.; CASTRO, P. A. Análises etnográficas das imagens sobre a realidade do aluno no enfrentamento das dificuldades e desigualdades na sala de aula. In: OLIVEIRA, I. B.; ALVES, N. BARRETO, R. G. (org.). Pesquisa em Educação métodos, temas e linguagens. Rio de Janeiro: DP\&A., 2005.

MEAD, M. The art and technology of fieldwork. In: NARROLL, R.; COHEN, R. (Ed.). A handbook of method in cultural Anthropology. New York: Columbia University. p. 246-265, 1973.

MIGNOLO, Walter D. Desobediência epistêmica: a opção descolonial e o significado de identidade em política. Cadernos de Letras da UFF: Dossiê: Literatura, língua e identidade, n.34, p.287-324, 2008

MILLS, C. W. Sobre o Artesanato Intelectual e outros ensaios. Rio de Janeiro: Zahar, 2009.

PELTO, P. Anthropological research: the structure of inquiry. New York: Harper and Row, 1970.

PEREIRA, T. V. Analisando alternativas para o ensino de Ciências Naturais: uma abordagem pós-estruturalista. Rio de Janeiro: Quartet; Faperj, 2012.

PINAR, W. Estudos curriculares: ensaios selecionados. São Paulo: Cortez, 2016.

VASCONCELLOS, S. de S. Multiplicidades da avaliação escolar: um estudo etnográfico sobre a repetência. Tese (Doutorado em Educação) - Universidade do Estado do Rio de Janeiro, 2016. 